Microscopy

Coming Events

2015

SMMS 2015: Single-Molecule Microscopy and Spectroscopy

September 14-16, 2015

London, UK

www.rsc.org/conferencesandevents/rscconferences/fd/ molecule-fd2015/index.asp

\section{SPIE Scanning Microscopies}

September 29-October 1, 2015

Monterey, CA

http://spie.org/x104030.xml

North American Molecular Beam

Conference (NAMBE 2015)

October 4-7, 2015

Mayan Riviera, Mexico

www2.avs.org/conferences/nambe/2015/index.htm

Materials Science \& Technology 2015

October 4-8, 2015

Columbus $\mathrm{OH}$

http://matscitech.org

Neuroscience 2015

October 17-21, 2015

Chicago, IL

Sponsor: Society for Neuroscience

www.sfn.org

American Vacuum Society

October 18-23, 2015

San Jose, CA

www.avs.org/symposium

Frontiers in Light Microscopy Symposium November 17, 2015

National Institutes of Health, Bethesda, MD

https://ncifrederick.cancer.gov/events/

LightMicroscopy

2015 MRS Fall Meeting \& Exhibition

November 29-December 4, 2015

Boston, MA

Sponsor: Materials Research Society (MRS)

www.mrs.org/fall2015

American Society for Cell Biology (ASCB)

2015 Annual Meeting

December 12-16, 2015

San Diego, CA

http://ascb.org/future-ascb-annual-meetings

2016

Microscopy \& Microanalysis 2016

July 24-28, 2016

Columbus, $\mathrm{OH}$

www.microscopy.org

2017

Microscopy \& Microanalysis 2017

July 23-27, 2017

St. Louis, MO

www.microscopy.org

2018

Microscopy \& Microanalysis 2018

August 5-9, 2018

Baltimore, MD

www.microscopy.org

2019

Microscopy \& Microanalysis 2019

August 4-8, 2019

Portland, OR

www.microscopy.org

2020

Microscopy \& Microanalysis 2020

August 2-6, 2020

Milwaukee, WI

www.microscopy.org

More Meetings and Courses

Check the complete calendar near the

back of this magazine.

\title{
AFM Solves the Mystery of the Slippery Slope
}

\author{
Stephen W. Carmichael \\ Mayo Clinic, Rochester, MN 55905 \\ carmichael.stephen@mayo.edu
}

Additives are used in lubricant oils for many important applications such as internal combustion engines and other machine components with moving parts. Among other things, these additives are crucial for improving the lubricant's ability to reduce friction and wear. A widely used additive is zinc dialkyldithiophosphate (ZDDP), which is one of the most successful anti-wear additives. However, due to the presence of $\mathrm{P}, \mathrm{S}$, and $\mathrm{Zn}, \mathrm{ZDDP}$ has the disadvantage of degrading catalytic converters in automobiles. It is known that ZDDP acts by forming a thin, solid layer called a "tribofilm" that grows at the interface of the sliding surfaces in contact with each other in the engine, and so it prevents direct metal-to-metal contact. This reduces wear dramatically. In spite of the fact that ZDDP has been used and studied for decades, the mechanisms governing tribofilm growth are not well understood, and this limits development of alternative lubricants that won't harm catalytic converters. This could all be changed by a recent study by Nitya Nand Gosvami, Jason Bares, Filippo Mangolini, Andrew Konicek, Dalia Yablon, and Robert Carpick [1]. Using atomic force microscopy (AFM), they monitored the growth and properties of ZDDP-derived tribofilms under conditions simulating the normal use of these lubricant additives.

It is known that ZDDP forms patchy films with pad-like features during the sliding process, but the mechanism behind the observation that they form a graded structure (with the composition changing with height) and stop growing at a certain thickness has been a mystery. On microscopic length scales, engineering surfaces are made of asperities, which resemble mountain peaks. So far, only macroscopic multi-asperity contacts had been analyzed, and most of the studies

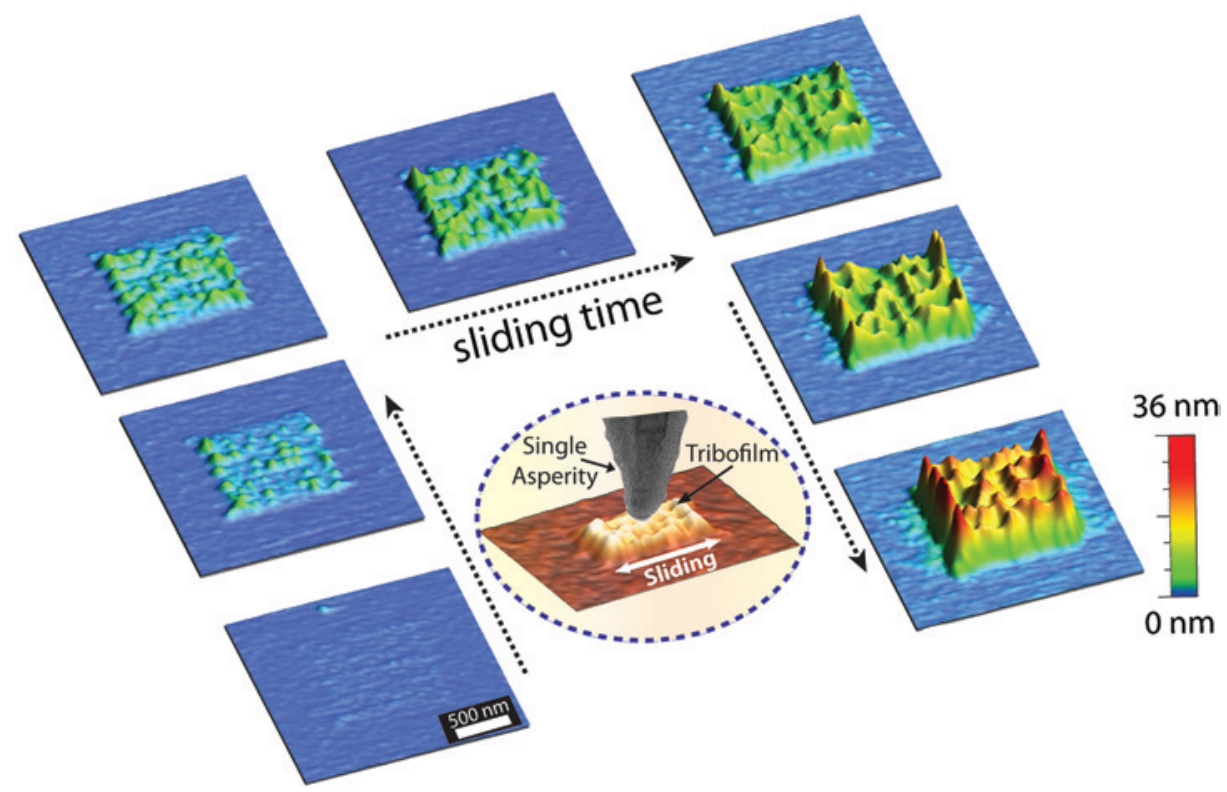

Figure 1: Periodically acquired $2 \mu \mathrm{m} \times 2 \mu \mathrm{m}$ AFM images of an iron oxide surface using a DLC-coated silicon AFM tip (single-asperity) immersed in ZDDP containing base stock, acquired at a non-perturbative load of $20.0 \pm 0.1 \mathrm{nN}$. The central $1 \mu \mathrm{m} \times 1 \mu \mathrm{m}$ regions were scanned at a significantly higher load of $340 \pm 2 \mathrm{nN}$ $(4.2 \pm 0.5 \mathrm{GPa})$. The images demonstrate progressive tribofilm growth where the higher load was applied. 


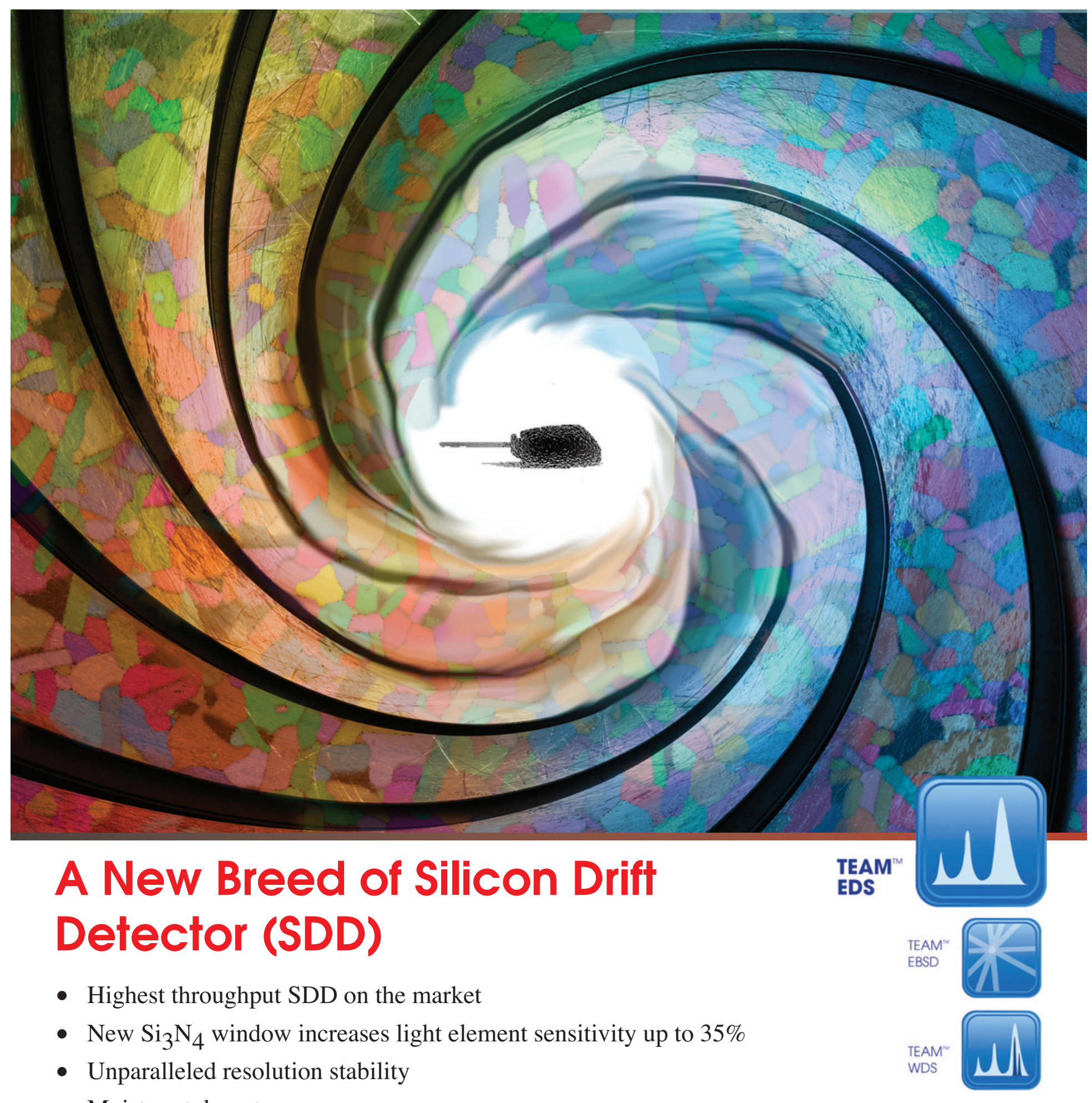

- Moisture tolerant

- Safe for plasma cleaning

Coming soon: exciting new product with market-leading speed and resolution.

Visit us at M\&M 2015, Booth \#445 to find out more! 
were performed ex situ. However, previous theoretical work had predicted that the tribofilm formation may be driven by direct pressure in the area of contact. For the first time, Gosvami et al. conducted in situ single-asperity studies of ZDDP tribofilm growth by immersing an AFM tip in the additive-infused oil, heating it up, and sliding in contact to form that tribofilm at nanoscale resolution. In situ singleasperity studies have several advantages: the formation of the tribofilm can be imaged directly at each step; the contact loads and geometries can be controlled and quantified; and the local tribofilm properties can be measured concurrently. The results are also ideal for comparison with atomistic simulations.

Among the many findings from this study, the authors showed that in AFM experiments under high stresses the growth rate of the tribofilms increased exponentially and reached a limiting value above a critical stress. An exponential increase of the tribofilm growth rate was observed as a function of temperature. For each given temperature and load, the volume of the tribofilms reached a constant value as a result of prolonged sliding. Within the subnanometer vertical resolution of their instrument, the tribofilms formed without any observable wear of the substrate, which in this case was iron oxide or silicon, in contrast to theories of growth that assume significant damage to and mixing in of the iron substrate to form the tribofilm. It was determined that the energy barrier for the relevant tribochemical reaction would be lower where the local stress is higher. The growth rate increased exponentially with either applied compressive stress or temperature, consistent with a thermally activated stress-assisted reaction rate model. This means that the self-limiting growth of the films can be explained by stress: as the film gets thicker, it "cushions" the applied load, leading to lower stress, and slowing growth of a less strongly bonded film. This stress effect would lead to a graded film, and eventually the stress is too low to promote growth.

Gosvami et al. suggested that their in situ approach can be directly applied to better understand molecular-level tribochemical phenomena and functionality such as the behavior of other important lubricant additives (for example, friction modifiers) or films formed in vapor-phase lubrication. This breakthrough study will lead the way to future studies that will improve the efficiency of internal combustion engines and other machine components and devices. The global economic impact of improved understanding of lubricant additives used in practical applications will be enormous!

\section{References}

[1] NN Gosvami et al., Science 348 (2015) 102-06.

[2] The author gratefully acknowledges Drs. Robert Carpick and Nitya Nand Gosvami for reviewing this article.

\section{uSight}

The new UV-VIS-NIR Micro-Spectroscopy Solution

When precise measurement matters

Introducing the new uSight series micro-spectroscopy solution that empower optical microscopes with UV-VIS-NIR spectroscopy measurement:

uSight- $\boldsymbol{X}$ for Laser-induced emission (i.e. Raman, PL) spectroscopy ; and uSight-2000 for absorbance, reflectance, transmittance spectroscopy

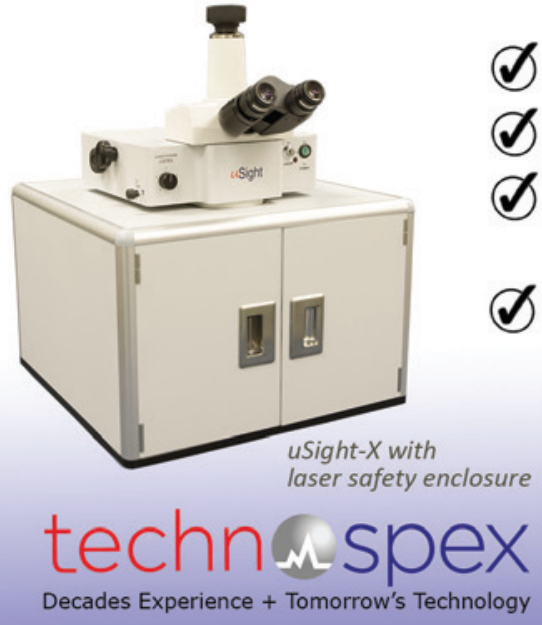

Affordable and compact design

Measurement spot $<1.0 u m$

High measurement spot accuracy with patent pending technique

Compatible with existing upright microscope

uSight-2000 mounted on a Nikon Ci-L microscope

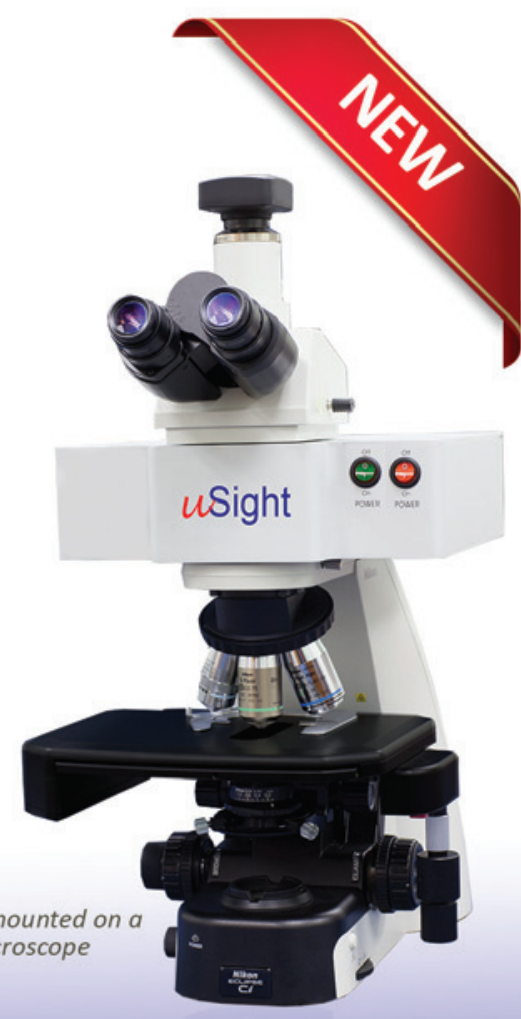

TechnoSpex Pte Ltd | 1092 Lower Delta Road \#04-01 Singapore 169203

Tel: +65 62766928 | Fax: +65 62761558 | sales@technospex.com 


\section{SPI Supplies UV Prep ${ }^{\mathrm{mI}}$ for SEM}

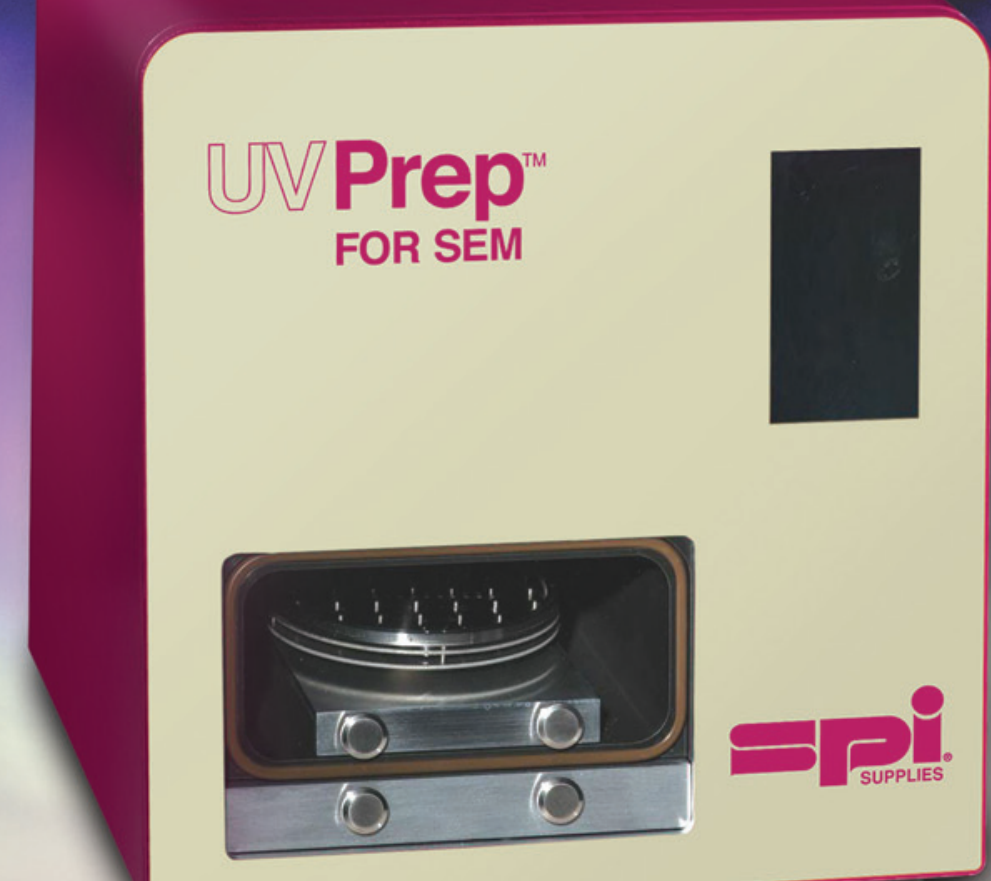

The UV Prep removes surface hydrocarbon contamination to reveal enhanced surface detail not otherwise visible in the SEM just a click away...2spi.com/uvp

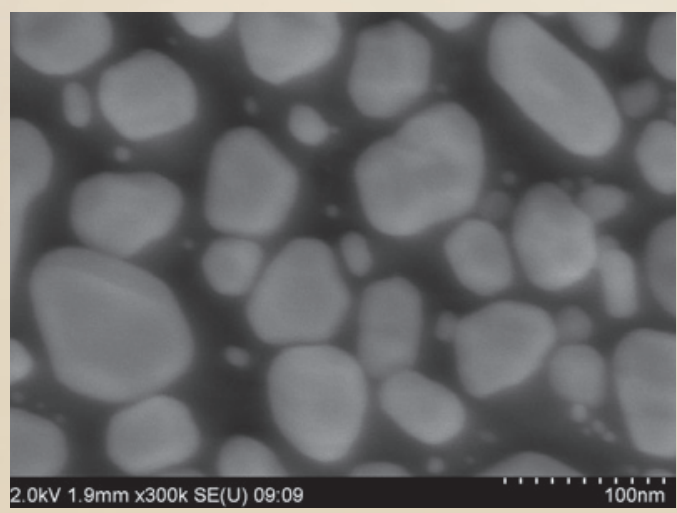

Mesoporous TiO2 Before UV Cleaning

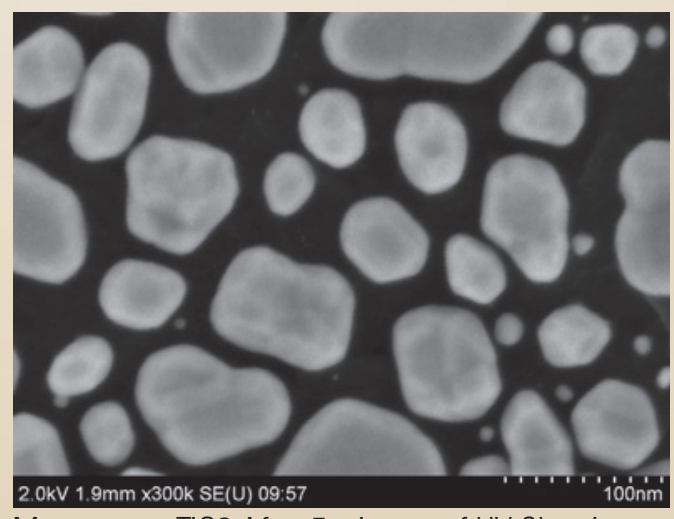

Mesoporous TiO2 After 5 minutes of UV Cleaning

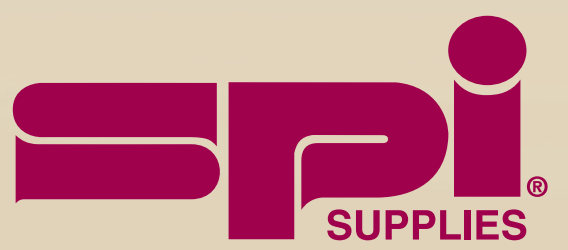

SPI Supplies Division of STRUCTURE PROBE, Inc. 